\title{
Rate Effects on Peak and Residual Strengths of Overconsolidated Clay in Ring Shear Tests
}

\author{
Nguyen Thanh Duong ${ }^{1 *}$, Motoyuki Suzuki $^{2}$ \\ ${ }^{1}$ Department of Engineering Geology, Hanoi University of Mining and Geology, 18 Vien Street, Duc Thang Ward, Bac Tu Liem District, \\ Hanoi, Vietnam \\ 2 Department of Civil and Environmental Engineering, Graduate School of Sciences and Technology for Innovation, Yamaguchi \\ University, 2-16-1, Tokiwadai, Ube, Yamaguchi 755-8611, Japan \\ * Corresponding author, e-mail: nguyenthanhduong@humg.edu.vn
}

Received: 03 September 2021, Accepted: 05 December 2021, Published online: 13 December 2021

\begin{abstract}
Overconsolidated (OC) clay soil is widely distributed in landslide slopes. This soil is often fissured, jointed, contains slickensides, and is prone to sliding. Thus, the shear strength behavior of OC clayey soil is complicated and has received much attention in the literature and in practice in terms of evaluating and predicting landslide stability. However, the behavior of the shear strength of OC clayey soil at different shear rates, as seen in ring shear tests, is still only understood to a limited extent and should be examined further, especially in terms of the residual strength characteristics. In this study, a number of ring shear tests were conducted on kaolin clay at overconsolidation ratios (OCRs) ranging from 1 to 6 under different shear displacement rates in the wide range of $0.02 \mathrm{~mm} / \mathrm{min}$ to $20.0 \mathrm{~mm} / \mathrm{min}$ to investigate the shear behavior and rate dependency of the shear strength of OC clay. Variations in the cohesion and friction angles of OC clay under different shear rates were also examined. The results indicated that the rate effects on the peak strength of $O C$ and normally consolidated (NC) clays are opposite at fast shear displacement rates. At the residual state, as with NC clay, the positive rate effect on the residual strength is also exhibited in OC clay, but at a lower magnitude. Regarding the shear strength parameters, the variations in the cohesion and friction angles of OC clay at different shear rates were found to be different at peak and residual states.
\end{abstract}

\section{Keywords}

rate effect, overconsolidated clay, peak strength, residual strength, dilation behavior, ring shear test

\section{Introduction}

Overconsolidated (OC) clayey soil is widely distributed in landslide slopes. It can form due to the release of stress (erosion of soil on the slope), changes in the groundwater level, secondary consolidation (aging), chemical bonding, and desiccation stress [1]. Many types of OC soil are fissured, jointed, contain slickensides, and are prone to instability $[2,3]$. Therefore, the shear behavior and shear strength (peak and residual strengths) of OC soil have received much attention in the literature and in practice in terms of evaluating and predicting slope stability [3-8].

Regarding the residual strength, the effects of the shear rate on the residual shear strength of soil have been widely investigated for many years [7, 9-15]. These investigations have shown that the residual strength is more or less dependent on the shear displacement rates. However, most of these investigations were conducted on normally consolidated (NC) soil. Since it is commonly known that the overconsolidation ratio (OCR) does not seem to affect the residual shear strength at slow shear rates [3, 15-18], the rate dependency of residual strength of OC soils has rarely been investigated. However, some previous studies have presented that the volumetric change of a specimen, resulting from dilatancy, significantly depends on the value of the OCR [5, 7, 19]. Vithana et al. [17] indicated that the shear surface structure of OC soil can be disturbed by dilation behavior during shearing and exhibited differently at different shear rates in ring shear tests. Recently, Scaringi et al. [20] showed that the increase of OCRs could lead to a decrease in the magnitude of positive rate dependency of the residual interface strength of clayey bi-material samples. Thus, the effect of the shear rate on the residual shear strength of an OC soil may differ from that of an 
NC soil and it needs to be further examined. With regard to the peak strength, the shear rate effect (strain rate effect) on the peak strength of both OC and NC soils has been widely investigated and clarified, especially in triaxial test [21-24]. Nevertheless, the rate effect on the peak shear strength of soil in ring shear test has not been examined and needs to clarified. In engineering practice, the shear strength parameters obtained from different shear rates can be used to different purposes such as providing a guide for designing some structures which require high precision of the design criterion or evaluating the stability of slopes which contain a pre-existing shear surface.

In this study, a series of Bishop-type ring shear tests [25] was conducted on remolded kaolin clay at different OCRs under different shear rates. The shear rates were varied in the considerably wide range of $0.02 \mathrm{~mm} / \mathrm{min}$ to $20.0 \mathrm{~mm} / \mathrm{min}$. The main objective of this study was to examine the shear strength behavior and rate dependency of both peak and residual strengths of OC clay and their relationship to the OCRs in ring shearing to provide a better understanding of shear strength measurement of OC soils. The variations in the cohesion and friction angles at both peak and residual strength states of the OC clay at different shear rates were also clarified.

\section{Materials and methods}

\subsection{Material, sample preparation, and test apparatus}

This study used commercial kaolin clay in the form of powder to prepare the remolded samples with high homogeneity. In Japan, commercial kaolin clay was commonly used for investigating some geotechnical properties of the soil, especially the residual strength [9, 26-28]. The physical properties of kaolin used in this study are as follows: density of the soil particles: $\rho_{\mathrm{s}}=2.645 \mathrm{~g} / \mathrm{cm}^{3}$, clay fraction content: $(<2 \mathrm{~mm}), C F=46 \%$, liquid limit: $w_{L}=77.5 \%$, and plasticity index: $P I=42.1 \%$. The oedometer tests were conducted on reconstituted kaolin sample prepared by the preconsolidation procedure in a consolidation tank under a pressure of $45 \mathrm{kPa}$. The coefficient of vertical consolidation $\left(c_{v}\right)$ of kaolin sample determined from oedometer test is $220.4 \mathrm{~cm}^{2} /$ day at $100 \mathrm{kPa}$ [29].

The dry powder kaolin clay was mixed with distilled water into a slurry at about twice its liquid limit. The slurry was then poured into a large consolidation tank with an inner diameter of $15 \mathrm{~cm}$, a height of $30 \mathrm{~cm}[9,29,30]$ and vacuum pressure of $70 \mathrm{kPa}$ was applied for at least 1 hour to release air bubbles The slurry samples were pre-consolidated at a normal stress of $98 \mathrm{kPa}$ in the consolidation tank until the primary consolidation was completed. The primary consolidation time was determined based on the $3 t$ method [31]. The ring-shaped specimens used in the ring shear tests were cut from the pre-consolidated samples using a cutting tool to have an outer diameter $(D)$ of $10.0 \mathrm{~cm}$, an inner diameter (d) of $6.0 \mathrm{~cm}(d / D=0.6)$, and a height of $2.0 \mathrm{~cm}$.

The Bishop-type ring shear apparatus [25] was employed in the present study. In this apparatus, the shear force, shear displacement, vertical displacement, and frictional force between the inner circumference of the shear box and the specimen were automatically recorded during shearing. The details of this apparatus have been reported in previous studies [9, 30, 32-34].

\subsection{Experimental procedure}

Each ring-shaped specimen, cut from the pre-consolidated samples, was placed in the shear box. A series of ring shear tests was carried out on reconstituted kaolin clay at different artificial OCRs. To create an artificial OCR, the specimens in the ring shear box were firstly consolidated at a given consolidation pressure $\left(\sigma_{c}\right)$ until the end of the primary consolidation, and then the normal stress was decreased to the desired value to obtain the required OCRs. The specimens were kept at the decreased normal stress until the end of the dilatancy process before shearing at this stress. The dilatancy process was confirmed based on the $3 t$ method.

To investigate the rate effect on the shear strength of the OC clay, specimens with artificial OCRs of 1,4 , and 6 were used. This range in OCR values is commonly used to investigate the shear strength behavior in ring shearing [17, 35]. Vithana et al. [17] reported that the peak strengths of landslide soils with OCRs of 4 and 6 at a slow shear rate of $0.01 \mathrm{~mm} / \mathrm{min}$ were almost identical. Thus, the present study strove to partly extend the research results of Vithana et al. [17]. Accordingly, the peak and residual strength behaviors of the soil in ring shear tests with OCRs of 4 and 6 will be extensively investigated at different shear rates from $0.02 \mathrm{~mm} / \mathrm{min}$ to $20 \mathrm{~mm} / \mathrm{min}$. The OCRs of 1,4 , and 6 consist of stress combinations of $98 / 98 \mathrm{kPa}$, $392 / 98 \mathrm{kPa}$, and $588 / 98 \mathrm{kPa}$, respectively, in which, the former value in each combination represents the consolidation pressure and the latter represents the normal stress at shearing. In this study, the specimens were consolidated at different pressures and sheared at the same normal stress. The experiment settings in the present study differ from those of Vithana et al. [17] in which the specimens were consolidated at the same pressure and sheared at 
different normal stresses. The specimens were sheared at shear displacement rates, $\delta$, in the 1000 times range from $0.02 \mathrm{~mm} / \mathrm{min}$ to $20.0 \mathrm{~mm} / \mathrm{min}$ to a shear displacement of about $314 \mathrm{~mm}$ (a rotation angle of 450 degrees) under the effective normal stress of $98 \mathrm{kPa}$.

To investigate the variations in the apparent cohesion and friction angles of the OC clay at different shear rates, three specimens were consolidated at $588 \mathrm{kPa}$ and then sheared at effective normal stress levels of 588, 392, and $98 \mathrm{kPa}$ which correspond to OCRs of $1,1.5$, and 6 , respectively. The shear displacement rates of 0.02 to $2.0 \mathrm{~mm} / \mathrm{min}$ were applied. In this procedure, the residual strength of clay with an OCR of $1.5(588 \mathrm{kPa} / 392 \mathrm{kPa})$ at different shear rates from 0.02 to $2.0 \mathrm{~mm} / \mathrm{min}$ was also evaluated.

To prevent the specimens from drying during testing, distilled water was immediately poured into the water bath after applying the consolidation pressure. To mitigate the contact friction between the upper and lower rings of the shear box and to minimize the soil extrusion from the shear surface, the gap between them was set at $0.1 \mathrm{~mm}$ before shearing. In the Bishop-type ring shear apparatus, the drainage condition is allowed during shearing.

\section{Experimental results and discussions}

\subsection{Ring shear behavior of $\mathrm{OC}$ clay under different shear rates}

The initial conditions and the test results of the kaolin specimens at different OCRs under different shear displacement rates are shown in Table 1. The residual strength $\left(\tau_{r}\right)$ and the residual stress ratio $\left(\tau / \sigma_{N}\right)_{r}$ were determined based on the hyperbolic curve approximation method [36]. The relationships of shear stress $\tau$ to shear displacement $\delta$ at different OCRs are presented in Figs. 1(a)-(c). As shown, the shear stress increases rapidly to reach the peak strength at a small shear displacement; then it begins to decline and is accompanied by an increase in shear displacement. The relationship between the shear displacement necessary to reach the peak state, $\delta^{\prime}$, and the different OCRs under sheardisplacement rates from $0.02 \mathrm{~mm} / \mathrm{min}$ to $20.0 \mathrm{~mm} / \mathrm{min}$ is shown in Fig. 2. This figure shows that the shear displacement required to reach the peak state decreases with the increasing OCRs for all the shear displacement rates in the above range. This confirms that an increase in the OCR leads to shear behavior with more brittle failure. However, the required shear displacement becomes mostly constant at OCRs of 4 and 6. These results are in good agreement with those of Vithana et al. [17].

\subsection{Rate effect on peak strength of OC clay}

Fig. 3 presents the relationship between the peak stress ratio, $\left(\tau / \sigma_{N}\right)_{p}$, and the shear displacement rates of the kaolin samples at different OCRs. It can be seen from this figure that, in the case of the OCR of $1,\left(\tau / \sigma_{N}\right)_{p}$ is almost constant at slow shear rates (less than or equal to $0.5 \mathrm{~mm} / \mathrm{min}$ ) and decreases with an increase in shear rates above $0.5 \mathrm{~mm} / \mathrm{min}$. These trends may be caused by the lack of any effect of the excess pore water pressure at slow shear rates and the delayed dissipation of excess pore water pressure during fast shearing at the peak state. The peak strengths (fully softened strength) of the $\mathrm{NC}$ samples at shear rates below and above $0.5 \mathrm{~mm} / \mathrm{min}$ can be referred to as the drained and partially drained/undrained shear strengths, respectively [9]. Like the NC specimens, the stress ratios at the peak state, $\left(\tau / \sigma_{N}\right)_{p}$, of the specimens at the OCRs of 4 and 6 are constant irrespective of the slow shear rates (less than or equal to $0.2 \mathrm{~mm} / \mathrm{min}$ ). Unlike the $\mathrm{NC}$ specimens, however, the peak stress ratios of the $\mathrm{OC}$ specimens tend to increase as the shear displacement rates become equal to or higher than $0.2 \mathrm{~mm} / \mathrm{min}$. The test results also show that the peak strengths of the OC specimens are higher than those of the NC specimens. Nevertheless, the difference in peak strengths of the kaolin clay at the OCRs of 4 and 6 is insignificant. This is consistent with the test results of Vithana et al. [17]. Although Vithana et al. [17] noted that the peak friction coefficient of Kamenose soil at the OCR of 4 was equal to that at the OCR of 6 , it did not reflect the effect of the shear displacement rates on the peak strength at the OCRs of 4 and 6. In the present study, the peak strength of kaolin clay at different OCRs was determined at different shear displacement rates from $0.02 \mathrm{~mm} / \mathrm{min}$ to $20.0 \mathrm{~mm} / \mathrm{min}$. The test results show that the peak strength of kaolin at the OCR of 4 is almost similar to that at the OCR of 6 , regardless of the shear displacement rates, as shown in Fig. 3.

In this study, when the OC specimens are subjected to shear in ring shearing, they show dilation behavior at the initial stage of shearing. This process leads to an increase in the void ratio under a drained condition. If the specimen is not allowed to be in a drained condition, a decrease in pore water pressure will appear. The excess pore water pressure inside the specimen may decrease to a negative value. The effect of excess pore water pressure on the peak strength behavior is closely related to the time it takes for the peak failure to occur. The test results showed that the peak strength of the OC specimens was reached after a very small shear displacement at all shear rates in the 
Notes for Table 1: *Some of these test data have been published in [9]

$p_{c}: \quad$ Consolidation pressure in consolidation tank (preparing sample)

$w_{0}: \quad$ Initial water content

$e_{0}$ : Initial void ratio

$\rho_{0}: \quad$ Initial wet density

$S_{r 0}: \quad$ Initial degree of saturation

$\sigma_{c}: \quad$ Consolidation pressure in shear box

$\sigma_{N 0}: \quad$ Initial normal stress

OCR: Overconsolidation ratio

$\left(\tau / \sigma_{N}\right)_{p}: \quad$ Stress ratio at peak state
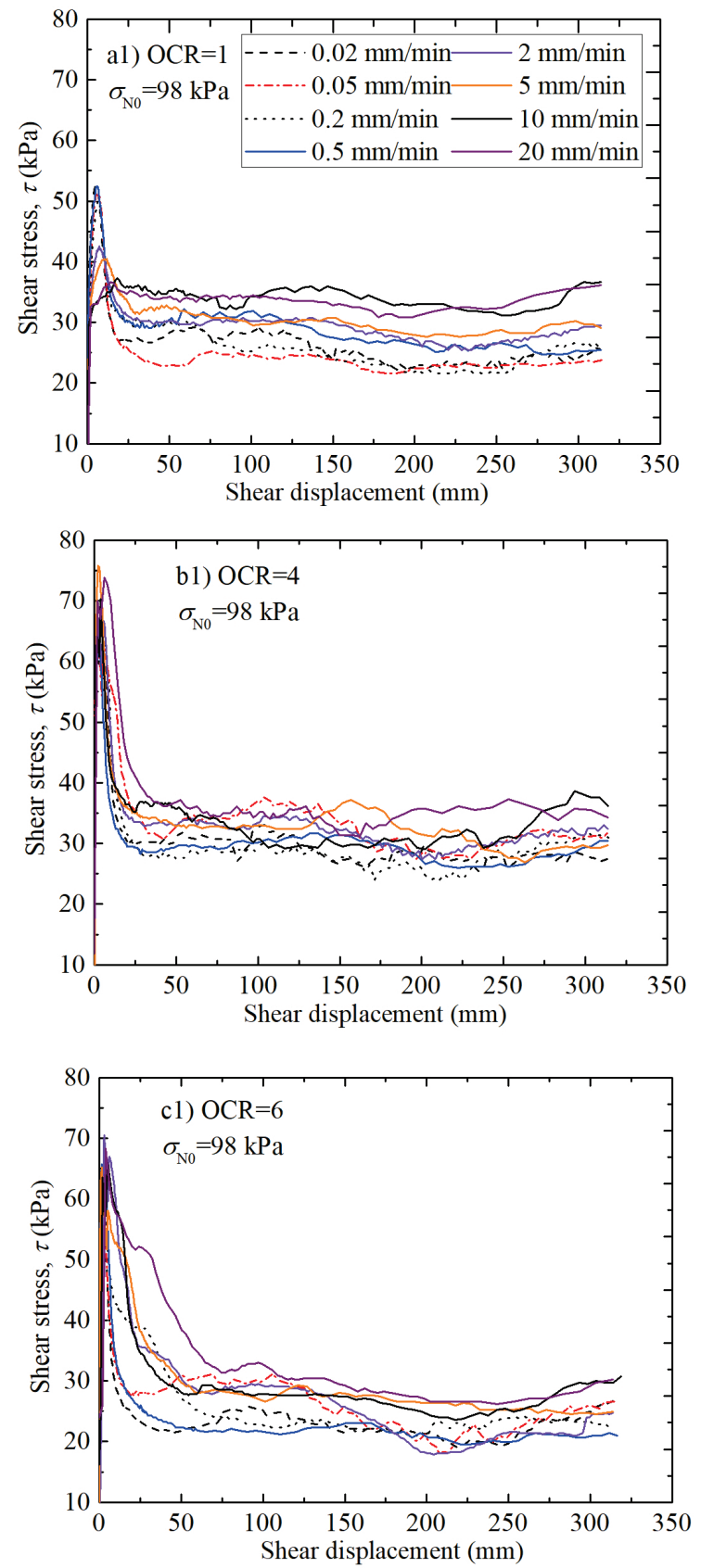

$\tau_{p}: \quad$ Peak strength

$\left(\tau / \sigma_{N}\right)_{r}$ : Residual stress ratio determined by hyperbolic curve approximation method [36]

$\tau_{r}: \quad$ Residual strength determined by hyperbolic curve approximation method [36]

$e_{c}: \quad$ Void ratio after consolidation

$e_{s}: \quad$ Void ratio before shearing (after swelling in the cases of OC specimens)

$e_{f}: \quad$ Void ratio after shearing

$\delta^{\prime}: \quad$ Shear displacement required to reach peak strength
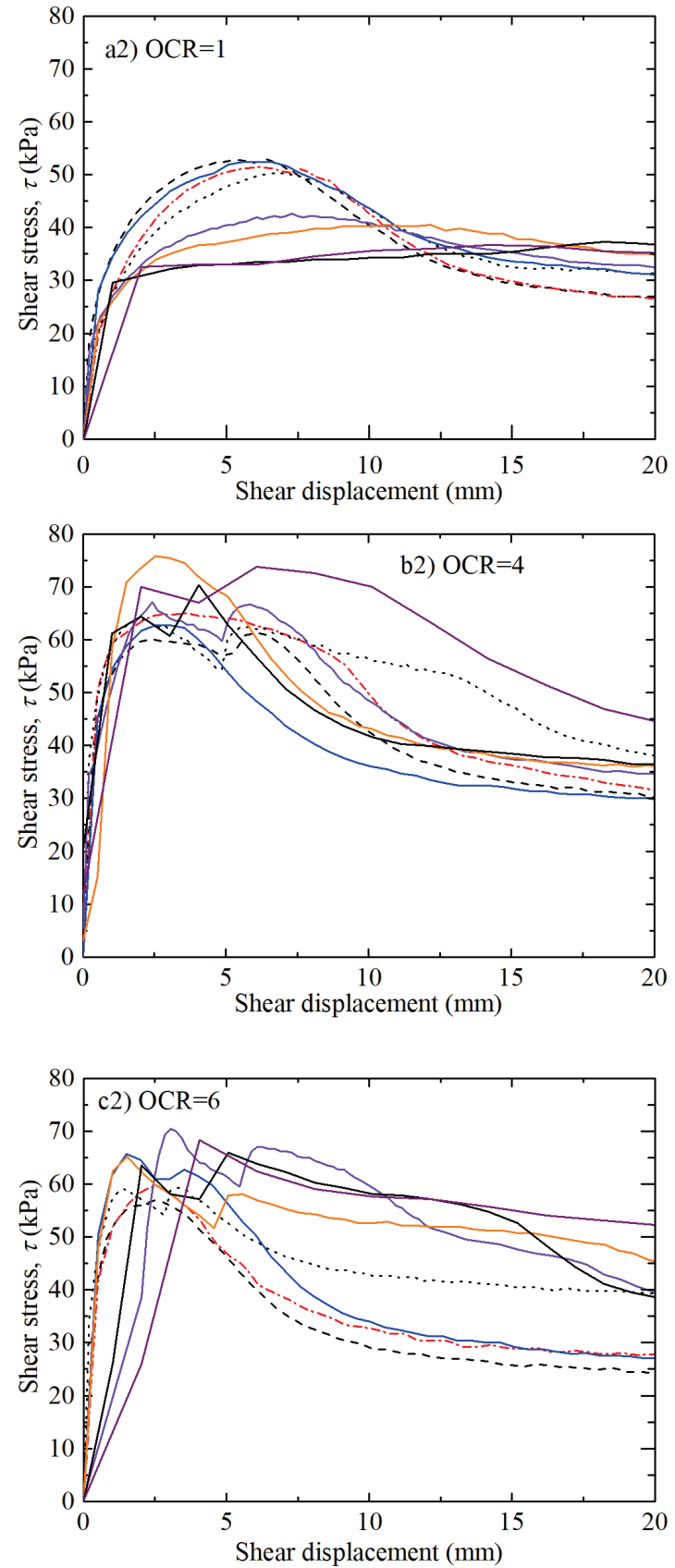

Fig. 1 Relationship of shear stress $\tau$ and shear displacement $\delta$ at different OCRs 
range of $0.02 \mathrm{~mm} / \mathrm{min}$ to $20.0 \mathrm{~mm} / \mathrm{min}$ (Fig. 2). At slow shear rates of less than or equal to $0.2 \mathrm{~mm} / \mathrm{min}$, there is sufficient time for the dissipation of pore water pressure before failure occurs. Thus, the peak shear stress at these shear rates is obtained under a drained condition. At shear rates above $0.2 \mathrm{~mm} / \mathrm{min}$, however, the time it takes to reach the peak stress ratios is short and may be insufficient for the dissipation of negative pore water pressure before failure occurs. Therefore, in this case, the peak shear stress or the peak stress ratios increase as the shear displacement rates increase and can be considered as partially drained or undrained behavior. The shear behavior may be moderately changed from drained to undrained through a partially drained condition as the shear rates increase [21].

The behaviors of the shear stress of the NC and OC samples at peak state with increasing shear rates in ring shear tests are schematically presented in Fig. 4. The peak shear stress of the NC kaolin clay (fully softened strength) at shear rates of less than or equal to $0.5 \mathrm{~mm} / \mathrm{min}$ and of the OC kaolin clay at shear rates of less than or equal to $0.2 \mathrm{~mm} / \mathrm{min}$ can be obtained under the drained condition. The partially drained or undrained condition is exhibited at shear rates above $0.5 \mathrm{~mm} / \mathrm{min}$ for the $\mathrm{NC}$ clay and at above $0.2 \mathrm{~mm} / \mathrm{min}$ for the OC clay due to the delayed dissipation of the pore water pressure. In the drained condition, the peak shear strength is independent of the shear rates due to the lack of any effect of the excess pore water pressure. In contrast, the peak strength under partially drained and undrained conditions exhibits shear rate dependency which is closely related to the delayed dissipation of the pore water pressure. These behaviors are consistent with those observed in triaxial tests [21-24] and direct shear tests [37]. In particular, Asaoka et al. [21] revealed that the partially drained shear strength of normally consolidated clay decreased, while the undrained shear strength in triaxial tests increased as the strain rate increased. At the strain rate of $4.9 \% / \mathrm{min}$, the partially drained shear strength was equal to the undrained shear strength. This indicates that the migration of pore water affected both the partially drained and undrained shear strengths. In this study, the delayed dissipation of the pore water pressure within the shear zone of OC specimens is closely related to the shear rate and affects the tendency of peak strength. This behavior is similar to shearing the sample at different values of saturation degree. Under undrained condition, the decrease in saturation degree will lead to a decrease in pore water pressure and results in an increase in the undrained peak shear strength [38].

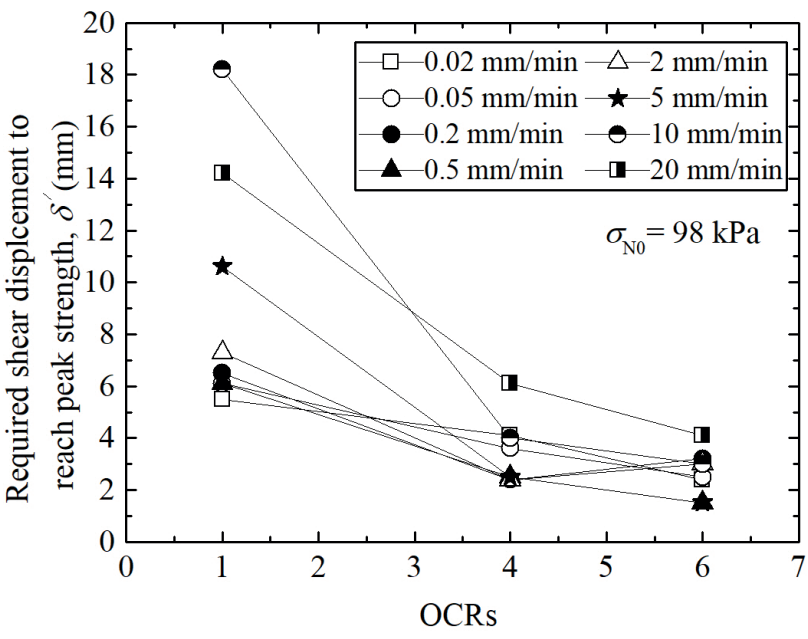

Fig. 2 Shear displacement required to reach peak strength at different OCRs

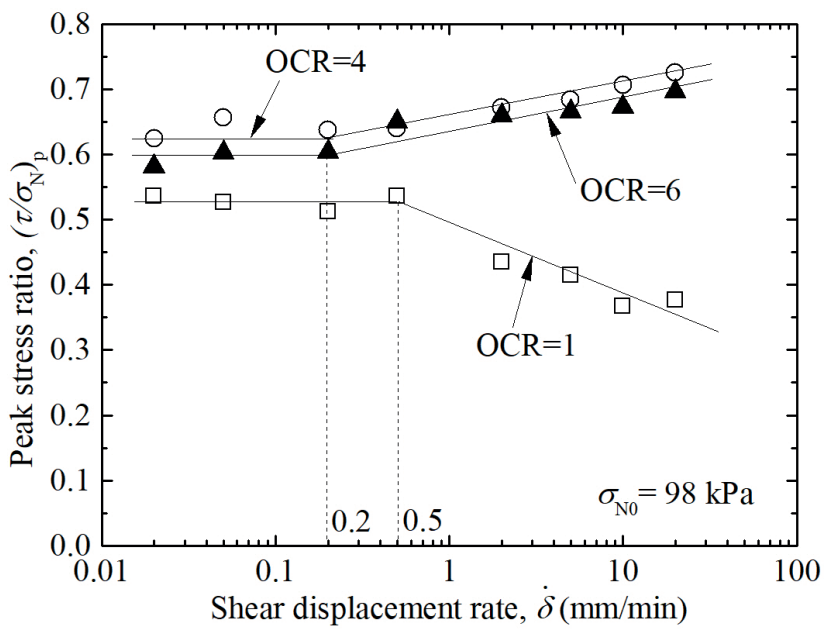

Fig. 3 Relationship between peak stress ratio and shear displacement rate at different OCRs

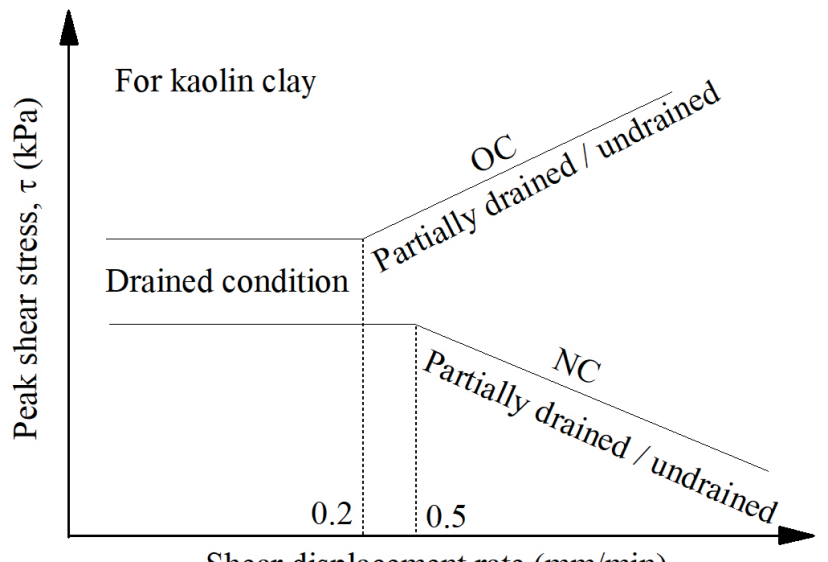

Shear displacement rate $(\mathrm{mm} / \mathrm{min})$

Fig. 4 Schematic diagram for change in shear strength of NC and OC samples at peak state at different shear rates 


\subsection{Rate effect on residual strength of $\mathrm{OC}$ clay}

Fig. 5 presents the relationship between the residual stress ratio, $\left(\tau / \sigma_{N}\right)_{r}$, and the shear displacement rates. For all the cases of OCRs, namely, 1, 4, and 6, the residual stress ratios show an increasing trend with the logarithm of shear displacement rates from $0.02 \mathrm{~mm} / \mathrm{min}$ to $20.0 \mathrm{~mm} / \mathrm{min}$. The increase in the residual strength of the kaolin clay with the increasing shear displacement rates could have been induced by the change in shear mode from sliding to turbulent $[7,10,16]$. In addition, the increase in the residual strength of the NC clay $(\mathrm{OCR}=1)$ could also be related to the soil extrusion through the gap between the upper and lower rings of the shear box [9]. Soil extrusion will lead to an increase in the final vertical displacement. Fig. 6 shows the relationship between final vertical displacement $\mathrm{nf}$ and the shear displacement rates for both $\mathrm{NC}$ and $\mathrm{OC}$ specimens. It can be seen from this figure that the final

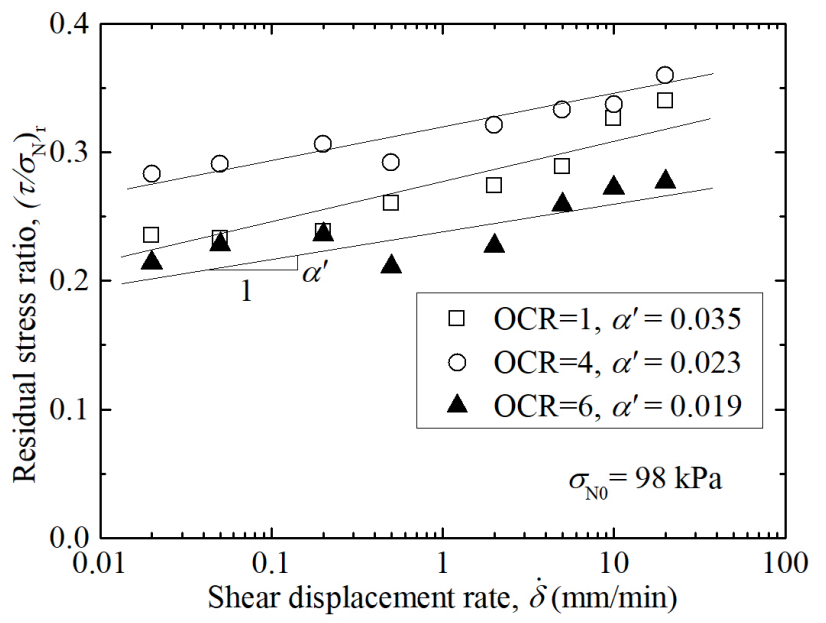

Fig. 5 Relationship between residual stress ratio and shear displacement rate at different OCRs

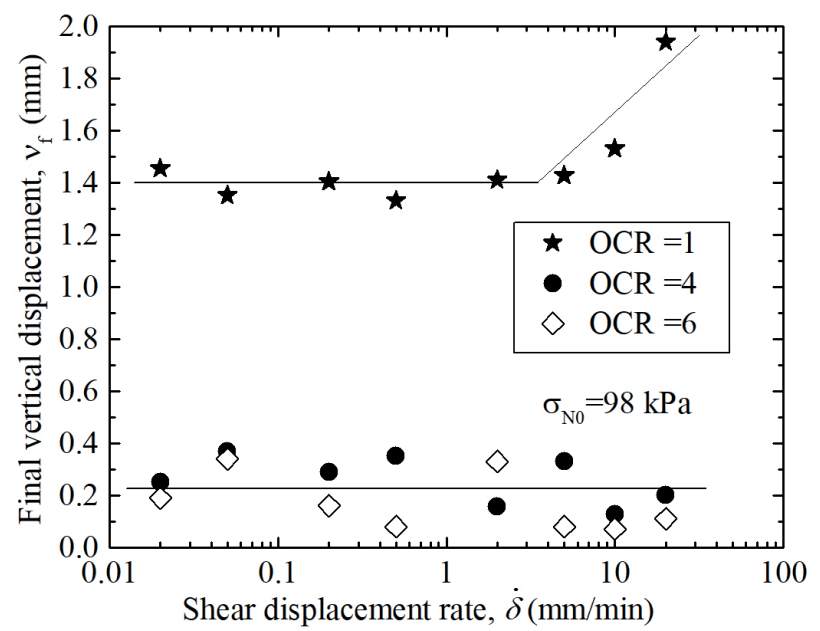

Fig. 6 Relationship between final vertical displacement $\mathrm{nf}$ and shear displacement rate at different OCRs vertical displacements of the $\mathrm{OC}$ specimens are almost similar, but much lower than those of the NC specimens, so that the positive rate effect on the residual strength of the OC clay may not be related to the soil extrusion. This reveals that OC samples should be used to determine the residual strength of soil using the Bishop-type ring shear device to reduce the soil leakage through the gap. This suggestion is similar to that of Stark [6], Stark and Eid [8] when using OC samples to determine the residual strength of soil using the Bromhead-type ring shear device.

For the OC samples, in addition to the structural change, the increase in residual strength at fast shear rates may be attributed to the existence of negative pore water pressure caused by dilation. However, the data in Fig. 6 show contractive behavior for all samples in the residual stage, including the OC specimens. Hence, the effect of the negative pore water pressure on the residual strength of OC clay can be excluded.

$\mathrm{Li}$ et al. [15] and $\mathrm{Xu}$ et al. [18] also investigated the rate dependency of the residual strength of OC clay. Nevertheless, there is no quantitative relationship between the OCRs and the magnitude of the rate effect could be drawn. In this study, rate effect coefficient $\alpha^{\prime}$ is used to quantitatively evaluate the effect of the OCR on the rate dependency of the residual strength. Parameter $\alpha^{\prime}$ is defined as follows [9]:

$\alpha^{\prime}=\frac{d\left(\tau / \sigma_{N}\right)_{r}}{d(\log \dot{\delta})}$

In Eq. (1), $\alpha^{\prime}$ is the rate effect coefficient; $d(\log \dot{\delta})$ is the change of shear rates; $d\left(\tau / \sigma_{N}\right)_{r}$ is the change of residual stress ratios in $d(\log \dot{\delta})$. The coefficient of the rate effect on the residual strength of kaolin at different OCRs is shown in Figs. 5 and 7, in which coefficient $\alpha^{\prime}$ in Fig. 5 is calculated based on the samples pre-consolidated at different stress levels $\left(\sigma_{c}=588,392\right.$, and $\left.98 \mathrm{kPa}\right)$, but sheared at the same effective normal stress $\left(\sigma_{N 0}=98 \mathrm{kPa}\right)$. In contrast, coefficient $\alpha^{\prime}$ in Fig. 7 is calculated based on the samples pre-consolidated at the same stress level $\left(\sigma_{c}=588 \mathrm{kPa}\right)$, but sheared at different effective normal stress levels $\left(\sigma_{N 0}=588,392\right.$, and $\left.98 \mathrm{kPa}\right)$. The values for $\alpha^{\prime}$ are summarized in Table 2.

The relationship between rate effect coefficient $\alpha^{\prime}$ and the OCRs is given in Fig. 8. This figure shows that the positive rate effect coefficient decreases as the OCRs increase, regardless of the magnitude of effective normal stress. In other words, the magnitude of the positive rate effect on the residual strength tends to decrease with the 


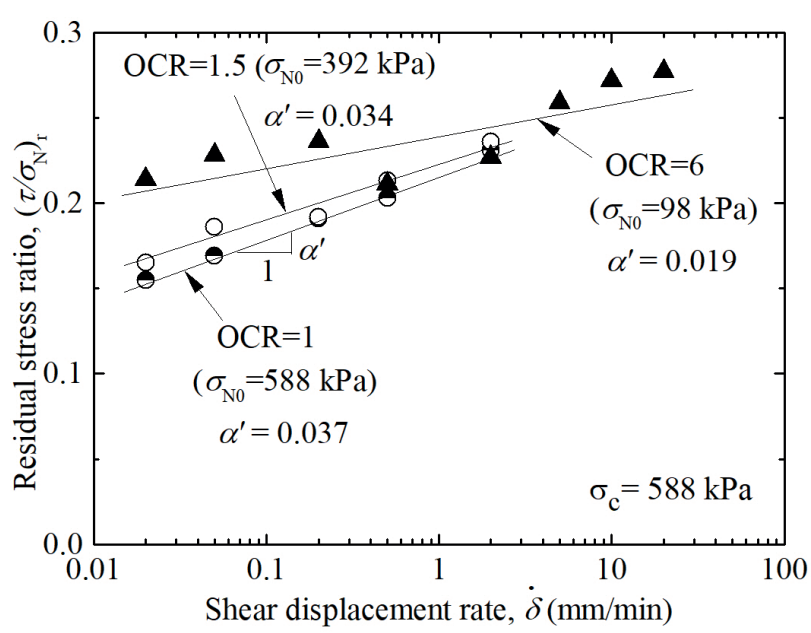

Fig. 7 Residual stress ratio of kaolin samples sheared at different normal stress levels

Table 2 Rate effect coefficient, $\alpha^{\prime}$

\begin{tabular}{ccccc}
\hline$\sigma_{c}(\mathrm{kPa})$ & $\begin{array}{c}\sigma_{N 0} \\
(\mathrm{kPa})\end{array}$ & $\begin{array}{c}\text { OCR } \\
\left(=\sigma_{c} / \sigma_{N 0}\right)\end{array}$ & $\begin{array}{c}\text { Shear displacement } \\
\text { rates }(\mathrm{mm} / \mathrm{min})\end{array}$ & $\alpha^{\prime}$ \\
\hline 98 & 98 & 1 & $0.02-20$ & 0.035 \\
392 & 98 & 4 & $0.02-20$ & 0.023 \\
588 & 98 & 6 & $0.02-20$ & 0.019 \\
588 & 392 & 1.5 & $0.02-2.0$ & 0.034 \\
588 & 588 & 1 & $0.02-2.0$ & 0.037 \\
\hline
\end{tabular}

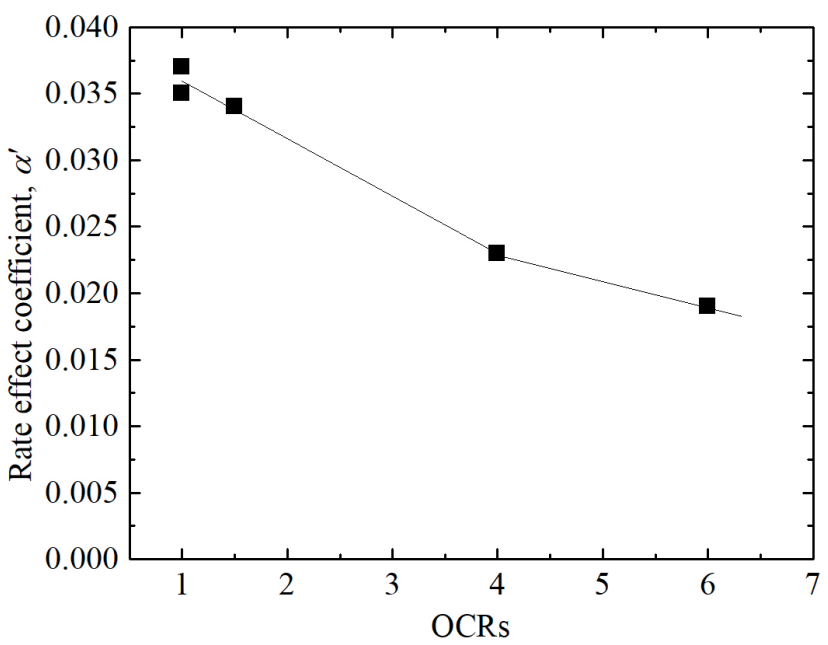

Fig. 8 Relationship between $\alpha^{\prime}$ and OCRs

increasing OCRs. This tendency is consistent with that discussed in Scaringi et al. [20]. Accordingly, the increase in OCRs may lead to a decrease in the positive rate effect on the residual strength at the interface of clayey bi-material [20]. As mentioned previously, the main reason for the positive rate effect is related to the change in shear mode from sliding to turbulent [7, 10, 16]. Vithana et al. [17] stated that the shear surface structure of OC soil may be disturbed by the dilation process. This leads to difficulty in reversing the face-face particle orientation (sliding) to turbulent shear behavior. This phenomenon may result in a lowering of the magnitude of the positive rate effect. Moreover, as mentioned above, the increase in soil extrusion of the NC specimens through the gap at fast shear rates may lead to an increase in the positive rate effect on the residual strength of the NC clay.

In addition, the magnitude of the rate dependency of the residual strength may be related to the void ratio of the samples. Li and Aydin [39] indicated that the positive rate effect may be decreased by the increase in soil density (decrease in void ratio). Figs. 9(a) and (b) show the changes in the void ratio of the samples at different OCRs in the case of shearing at the same effective normal stress and different effective normal stress levels, respectively. The void ratios were calculated after consolidation, before and after shearing, based on changes in the vertical displacement of the specimens. It should be noted that the void ratios after

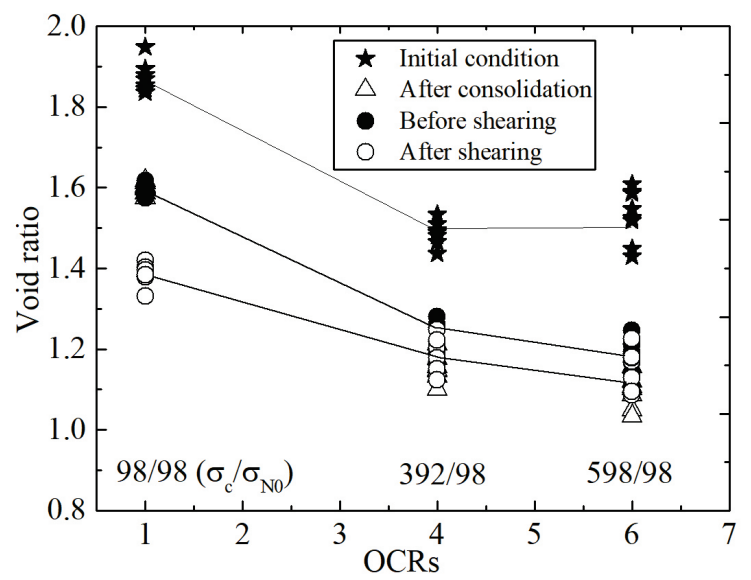

(a) $\sigma_{\mathrm{N} 0}=98 \mathrm{kPa}$

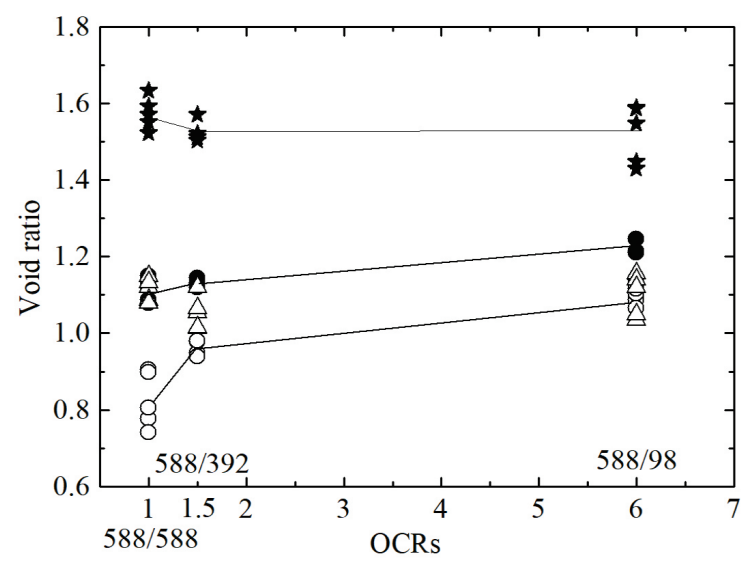

(b) $\sigma_{c}=588 \mathrm{kPa}$

Fig. 9 Changes in void ratio of samples at different OCRs: a) preconsolidated at different pressures and sheared at the same effective normal stress and $b$ ) pre-consolidated at the same pressure and sheared at different effective normal stress levels 
shearing may not totally reflect the real values because of soil leakage through the gap between the upper and lower parts of the shear box, especially at the OCR of 1 . However, they more or less reflect the relationship between the soil density and the rate dependency of the residual strength. As shown in Fig. 9(a), the void ratios before and after shearing decrease with the increasing OCRs.

The relationship between the rate effect coefficient and the average void ratio after the shearing of a sample at different OCRs is seen in Fig. 10. As reflected in the figure, the rate effect coefficient decreases as the average void ratio after shearing decreases (increasing OCRs). Hence, the findings of Li and Aydin [39] seem to be consistent with the change in the positive rate effect coefficient when shearing at the same effective normal stress. However, Fig. 9(b) indicates that the void ratios before and after shearing tend to increase with the increasing OCRs due to dilation behavior during the unloading process. This means that the magnitude of the positive rate effect on the residual strength of the OC samples may not be totally related to the change in the void ratio (soil density). Therefore, the disturbance of the shear surface structure of the OC samples subjected to shearing, especially at fast shear rates, can be an additional cause of the decrease in magnitude of the positive rate effect with increasing OCRs. As described above, the soil extrusion through the gap at the middle level of the shear box in the NC samples is much higher than that in the OC samples, and higher soil extrusion may lead to an increase in the residual strength [9]. Hence, the decrease in magnitude of the positive rate effect on the residual strength as the OCRs increase can be attributed to less soil extrusion through the gap for the OC specimens (mechanical effect).

\subsection{Variations in cohesion and friction angles of $\mathrm{OC}$ clay under different shear rates}

The variations in the cohesion and friction angles of the OC samples were investigated under shear displacement rates of 0.02 to $2.0 \mathrm{~mm} / \mathrm{min}$. The tests were conducted on individual specimens under different effective normal stress levels equal to different OCRs. Accordingly, at each shear rate, three specimens were firstly consolidated under the effective normal stress of $588 \mathrm{kPa}$; then they were sheared at effective normal stress levels of 588,392 , and $98 \mathrm{kPa}$, respectively (Table 1).

The relationships between the effective normal stress and the shear stress at the peak and residual states are shown in Figs. 11(a) and (b), respectively. It can be seen that all the linear regressions are almost parallel at the peak state (Fig. 11(a)), whereas the slope of the linear regression

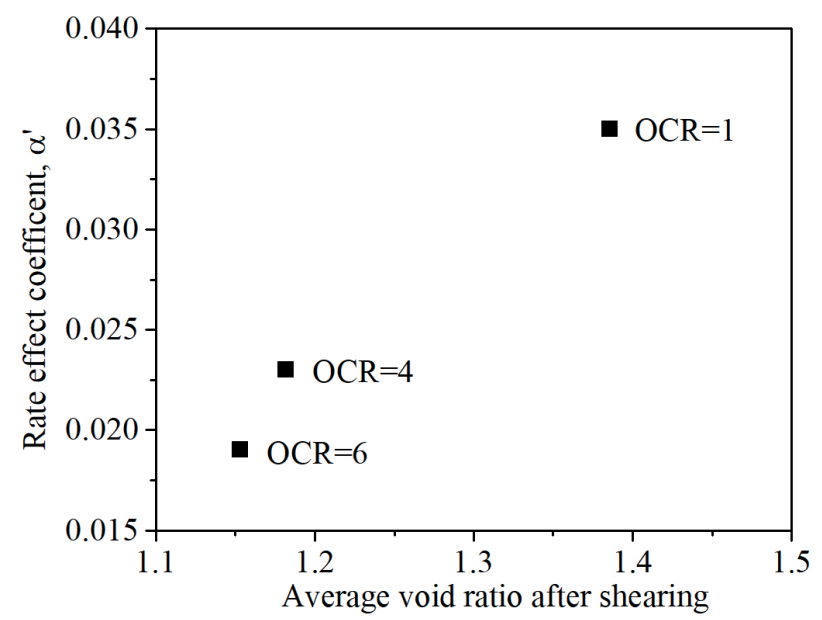

Fig. 10 Relationship between rate effect coefficient and average void ratio after shearing

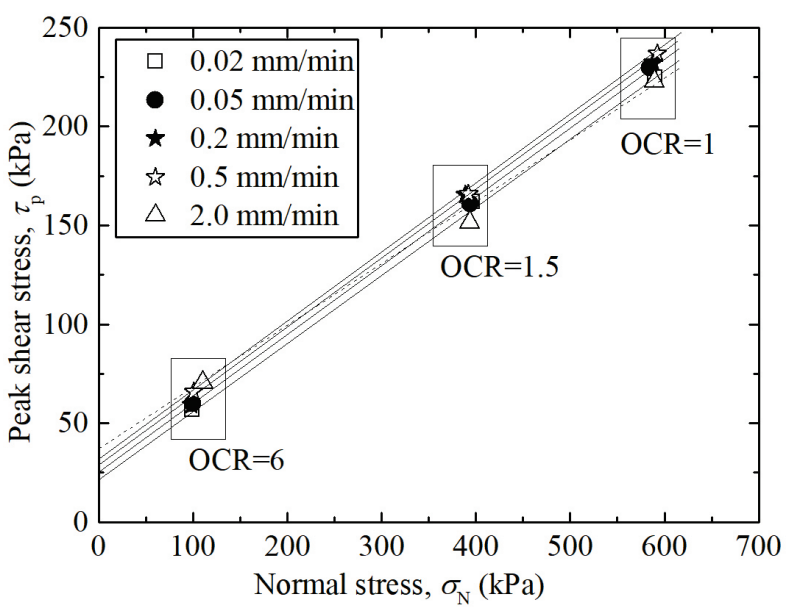

(a)

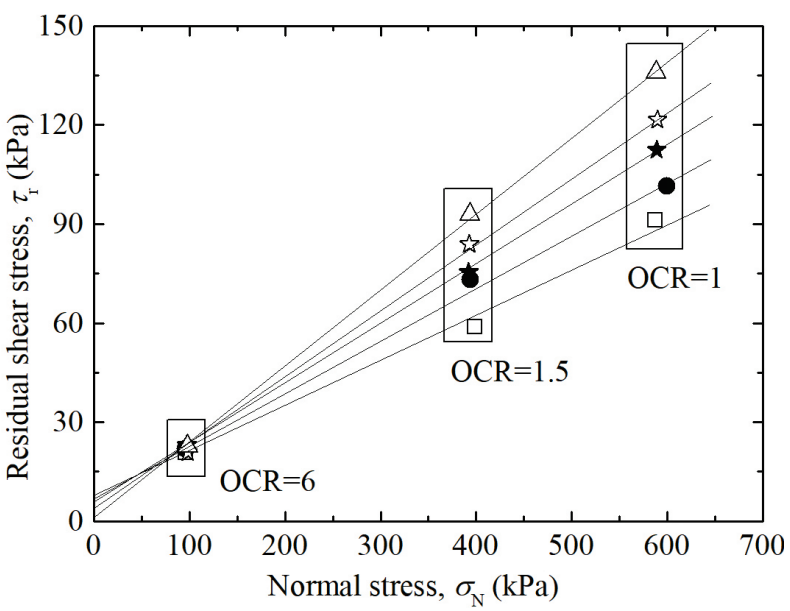

(b)

Fig. 11 Relationship of (a) peak shear strength and (b) residual shear strength to normal stress

increases with increasing shear displacement rates at the residual state (Fig. 11(b)). This may reflect the difference in the variations in cohesion and friction angles at the peak and residual states of the $\mathrm{OC}$ samples. 
Table 3 Results of cohesion intercept and internal friction angles of OC clay

\begin{tabular}{|c|c|c|c|c|c|c|}
\hline \multirow[b]{2}{*}{ No } & \multirow[b]{2}{*}{$\begin{array}{l}\text { Shear disp. rates } \\
(\mathrm{mm} / \mathrm{min})\end{array}$} & \multirow[b]{2}{*}{ Specimen types } & \multicolumn{2}{|c|}{ Peak strength } & \multicolumn{2}{|c|}{ Residual strength } \\
\hline & & & $\begin{array}{c}\text { Cohesion intercept } \\
c_{p}(\mathrm{kPa})\end{array}$ & $\begin{array}{l}\text { Internal friction } \\
\text { angle, } \phi_{p}(\mathrm{deg})\end{array}$ & $\begin{array}{c}\text { Cohesion intercept, } \\
c_{r}(\mathrm{kPa})\end{array}$ & $\begin{array}{l}\text { Internal friction } \\
\text { angle, } \phi_{r}(\mathrm{deg})\end{array}$ \\
\hline 1a & 0.02 & $\mathrm{OC}$ & 24.3 & 18.8 & 7.3 & 8.1 \\
\hline $1 b$ & 0.02 & $\mathrm{NC}$ & 15.8 & 19.8 & 6.8 & 9.0 \\
\hline 2 & 0.05 & $\mathrm{OC}$ & 24.5 & 19.3 & 7.8 & 9.0 \\
\hline 3 & 0.2 & $\mathrm{OC}$ & 25.5 & 19.5 & 4.9 & 10.3 \\
\hline 4 & 0.5 & $\mathrm{OC}$ & 30.3 & 19.1 & 1.2 & 11.6 \\
\hline 5 & 2.0 & $\mathrm{OC}$ & 34.0 & 17.5 & 0.5 & 13.0 \\
\hline
\end{tabular}

The calculated results for the apparent cohesion and friction angles at both the peak and residual states of the $\mathrm{OC}$ specimens are summarized in Table 3. The residual strength parameters of the NC kaolin sample at a slow shear rate of $0.02 \mathrm{~mm} / \mathrm{min}$ were also determined. The results confirm that the stress history (OCR) has almost no effect on the residual strength.

The variations in the apparent cohesion and friction angles at the peak and residual states under different shear displacement rates are presented in Figs. 12(a) and (b). As shown in Fig. 12(a), the peak cohesion intercept tends to increase as the shear rates increase at above $0.2 \mathrm{~mm} /$ min, while the peak internal friction angle is almost independent of the shear rates in the range of 0.02 to $2.0 \mathrm{~mm} /$ min. As mentioned previously, negative pore water pressure may be generated at the peak failure when the OC specimens are subjected to shear. With the existence of negative pore water pressure (matric suction), the total peak cohesion can be composed of true cohesion and apparent cohesion. True cohesion is thought to be reproduced by chemical cementation due to aging, interlocking between particles, and bonding stress due to negative pressure [26]. The increase in the peak strength of OC kaolin clay as the shear rates increase is due to the increase in true cohesion which can be attributed to the delayed dissipation of negative pore water pressure (suction). As reported by Ho and Fredlund [40], the increase in shear strength due to suction can be attributed to the increase in cohesion. In contrast, the negative pore water pressure may not affect the peak friction angle [41, 42]. The research results of Han et al. [43] also indicated that the peak friction angle of highly overconsolidated clay (OCRs from 7 to 56) in triaxial tests appeared to be independent of the strain rates. The tendency of cohesion and internal friction angles at the peak state of the OC kaolin clay with increasing shear rates is consistent with the tendency of the peak stress ratios, as shown in Fig. 3.

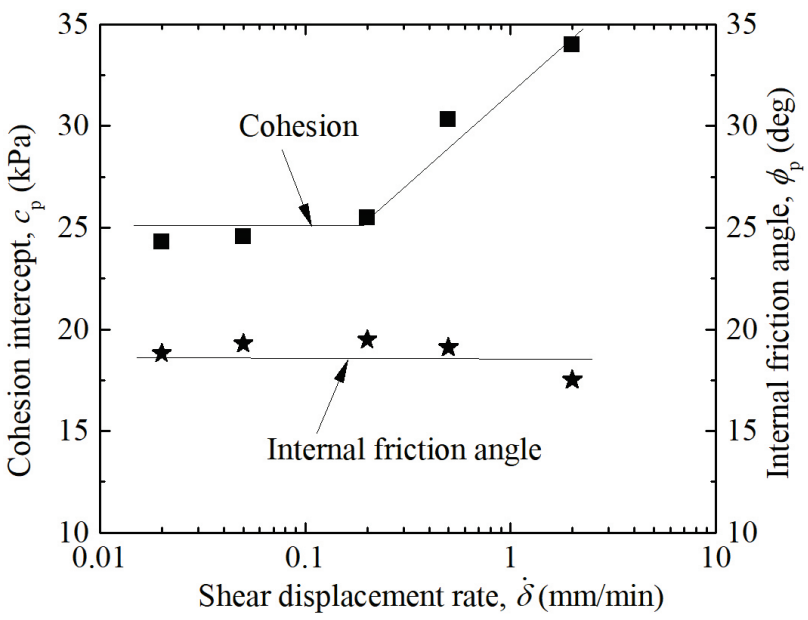

(a)

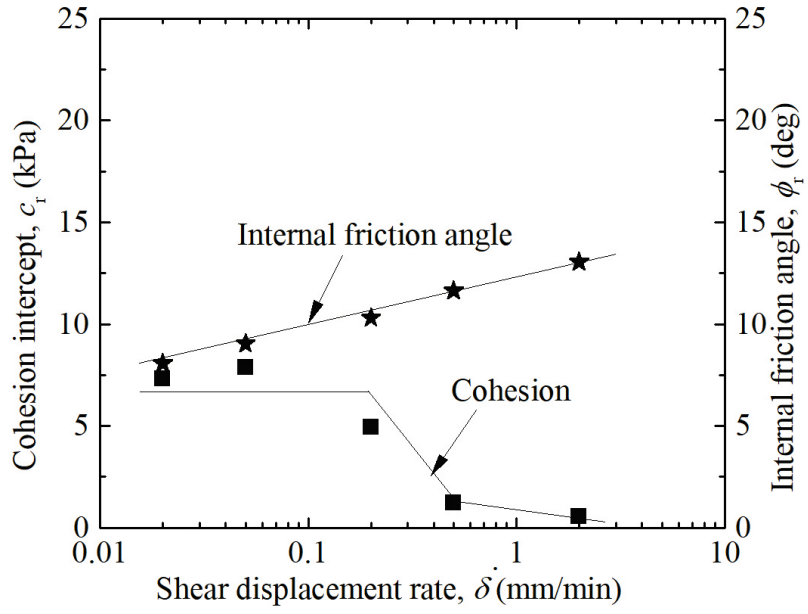

(b)

Fig. 12 Variations in cohesion and internal friction angles of OC clay at different shear rates at: a) peak state and b) residual state

At the residual state, unlike at the peak state, the friction angle increases, whereas the cohesion remains constant and then tends to slightly decrease as the shear displacement rates increase (Fig. 12(b)). Although the residual cohesion decreases with the shear displacement rates, it has no effect on the overall tendency of the residual stress ratio, as mentioned above, because the residual cohesion is insignificant. 
Therefore, the increase in the residual strength of OC clay with increasing shear rates is attributed to the increase in the internal friction angles of the soil on the slip surface.

\section{Conclusions}

This paper has presented an experimental investigation of ring shear tests conducted on kaolin clay at OCRs ranging from 1 to 6 . The tests were conducted at shear rates ranging from $0.02 \mathrm{~mm} / \mathrm{min}$ to $20.0 \mathrm{~mm} / \mathrm{min}$ and under normal stress levels of 98,392 , and $588 \mathrm{kPa}$, respectively. Based on an analysis of the test results, the main conclusions can be drawn as follows:

For both $\mathrm{NC}$ and $\mathrm{OC}$ kaolin clays, the shear behavior switches from drained to partially drained/undrained conditions at shear rates exceeding $0.2-0.5 \mathrm{~mm} / \mathrm{min}$. However, at shear rates above $0.5 \mathrm{~mm} / \mathrm{min}$ for $\mathrm{NC}$ clay and $0.2 \mathrm{~mm} / \mathrm{min}$ for $\mathrm{OC}$ clay, the rate effect on the peak strength of $\mathrm{NC}$ and OC kaolin clays occurs due to different tendencies. This shows that a change in the overconsolidation ratio affects the type of rate effect on the peak strength of kaolin clay in ring shearing.

\section{References}

[1] Hanzawa, H., Adachi, K. "Overconsolidation of alluvial clays", Soils and Foundations, 23(4), pp. 106-118, 1983.

https://doi.org/10.3208/sandf1972.23.4_106

[2] Picarelli, L., Urciuoli, G., Mandolini, A., Ramondini, M. "Softening and instability of natural slopes in highly fissured plastic clay shales", Natural Hazards and Earth System Sciences, 6(4), pp. 529-539, 2006. https://doi.org/10.5194/nhess-6-529-2006

[3] Skempton, A. W. "Long-term stability of clay slopes", Géotechnique, 14(2), pp. 77-102, 1964.

https://doi.org/10.1680/geot.1964.14.2.77

[4] Mikoš, M., Petkovšek, A., Majes, B. "Mechanisms of landslides in over-consolidated clays and flysch", Landslides, 6(4), pp. 367-371, 2009.

https://doi.org/10.1007/s10346-009-0171-6

[5] Skempton, A. W. "First-time slides in over-consolidated clays", Géotechnique, 20(3), pp. 320-324, 1970.

https://doi.org/10.1680/geot.1970.20.3.320

[6] Stark, T. D. "Measurement of drained residual strength of overconsolidated clays", Transportation Research Record, 1479, pp. 26-34, 1995.

[7] Skempton, A. W. "Residual strength of clays in landslides, folded strata and the laboratory", Géotechnique, 35(1), pp. 3-18, 1985. https://doi.org/10.1680/geot.1985.35.1.3

[8] Stark, T. D., Eid, H. T. "Modified Bromhead ring shear apparatus", Geotechnical Testing Journal 16(1), pp. 100-107, 1993. https://oi.org/10.1520/GTJ10272J

[9] Duong, N. T., Suzuki, M., Van Hai, N. "Rate and acceleration effects on residual strength of kaolin and kaolin-bentonite mixtures in ring shearing", Soils and Foundations, 58(5), pp. 1153-1172, 2018. https://doi.org/10.1016/j.sandf.2018.05.011
The positive rate effect on the residual strength is exhibited in both NC and OC kaolin clays. However, the magnitude of the positive rate effect on the residual strength decreases as the OCRs increase. In other words, the change in stress history (OCR) not only affects the type of rate effect on the peak strength, but also affects the rate dependence in the residual state.

The variations in the cohesion and internal friction angles of OC kaolin clay at peak and residual states under different shear displacement rates are different. In the studied range of shear rates, the primary parameter governing the variation of peak strength of OC clay is the cohesion, whereas for the variation of residual strength of OC clay, the main control parameter is the internal friction angle.

\section{Acknowledgement}

This research is funded by Vietnam National Foundation for Science and Technology Development (NAFOSTED) under grant number 105.08-2019.315.

[10] Tika, T. E., Vaughan, P. R., Lemos, L. J. "Fast shearing of pre-existing shear zones in soil", Géotechnique, 46(2), pp. 197-233, 1996. https://doi.org/10.1680/geot.1996.46.2.197

[11] Wang, L., Han, J., Liu, S., Yin, X. "Variation in Shearing Rate Effect on Residual Strength of Slip Zone Soils Due to Test Conditions", Geotechnical and Geological Engineering, 38, pp. 2773-2785, 2020. https://doi.org/10.1007/s10706-020-01186-9

[12] Wang, L., Han, J., Yin, X., Liu, S. "Effect of moisture content and shearing speed on shear zone structure in fine-grained soils at large displacement", Arabian Journal of Geosciences, 13(6), Article No. 247, 2020.

https://doi.org/10.1007/s12517-020-5237-8

[13] Wang, Y., Cong, L. "Effects of water content and shearing rate on residual shear stress", Arabian Journal for Science and Engineering, 44(10), pp. 8915-8929, 2019.

https://doi.org/10.1007/s13369-019-03922-7

[14] Kimura, S., Nakamura, S., Vithana, S. B., Sakai, K. "Shearing rate effect on residual strength of landslide soils in the slow rate range", Landslides, 11(6), pp. 969-979, 2014. https://doi.org/10.1007/s10346-013-0457-6

[15] Li, D., Yin, K., Glade, T., Leo, C. "Effect of over-consolidation and shear rate on the residual strength of soils of silty sand in the Three Gorges Reservoir", Scientific Reports, 7(1), Article No. 5503, 2017. https://doi.org/10.1038/s41598-017-05749-4

[16] Lupini, J. F., Skinner, A. E., Vaughan, P. R. "The drained residual strength of cohesive soils", Géotechnique, 31(2), pp. 181-213, 1981. https://doi.org/10.1680/geot.1981.31.2.181

[17] Vithana, S. B., Nakamura, S., Kimura, S., Gibo, S. "Effects of overconsolidation ratios on the shear strength of remoulded slip surface soils in ring shear", Engineering Geology, 131-132, pp. 29-36, 2012. https://doi.org/10.1016/j.enggeo.2012.01.015 
[18] Xu, C., Wang, X., Lu, X., Dai, F., Jiao, S. "Experimental study of residual strength and the index of shear strength characteristics of clay soil", Engineering Geology, 233, pp. 183-190, 2018. https://doi.org/10.1016/j.enggeo.2017.12.004

[19] Hattab, M., Hicher, P. Y. "Dilating behaviour of overconsolidated clay", Soils and Foundations, 44(4), pp. 27-40, 2004. https://doi.org/10.3208/sandf.44.4_27

[20] Scaringi, G., Hu, W., Xu, Q., Huang, R. "Shear-rate-dependent behavior of clayey bimaterial interfaces at landslide stress levels", Geophysical Research Letters, 45(2), pp. 766-777, 2018. https://doi.org/10.1002/2017GL076214

[21] Asaoka, A., Nakano, M., Noda, T. "Soil-water coupled behaviour of saturated clay near/at critical state", Soils and Foundations, 34(1), pp. 91-105, 1994. https://doi.org/10.3208/sandf1972.34.91

[22] Mun, W., Teixeira, T., Balci, M. C., Svoboda, J., McCartney, J. S. "Rate effects on the undrained shear strength of compacted clay", Soils and Foundations, 56(4), pp. 719-731, 2016. https://doi.org/10.1016/j.sandf.2016.07.012

[23] Quinn, T. A. C., Brown, M. J. "Effect of strain rate on isotropically consolidated kaolin over a wide range of strain rates in the triaxial apparatus", In: Proceedings of the 5th International Symposium on Deformation Characteristics of Geomaterials, Seoul, Republic of Korea, 2011, pp. 607-613.

[24] Sheahan, T. C., Ladd, C. C., Germaine, J. T. "Rate-dependent undrained shear behavior of saturated clay", Journal of Geotechnical Engineering, 122(2), pp. 99-108, 1996. https://doi.org/10.1061/(ASCE)0733-9410(1996)122:2(99)

[25] Bishop, A. W., Green, G. E., Garga, V, K., Andresen, A., Brown, J. D. "A new ring shear apparatus and its application to the measurement of residual strength", Géotechnique, 21(4), pp. 273-328, 1971. https://doi.org/10.1680/geot.1971.21.4.273

[26] Suzuki, M., Tsuzuki, S., Yamamoto, T. "Residual strength characteristics of naturally and artificially cemented clays in reversal direct box shear test", Soils and Foundations, 47(6), pp. 1029-1044, 2007. https://doi.org/10.3208/sandf.47.1029

[27] Tiwari, B., Padgett, J., Ajmera, B., Bieda, A. "Effect of Mineralogical Composition and Pore Water Chemistry on Shearing Rate Dependent Residual Shear Strength of Soil", In: Geo-Congress 2020: Modeling, Geomaterials, and Site Characterization, pp. 332-340, 2020

[28] Tiwari, B., Marui, H. "Estimation of residual shear strength for bentonite-kaolin-Toyoura sand mixture", Journal of the Japan Landslide Society, 40(2), pp. 124-133, 2003. https://doi.org/10.3313/jls.40.124

[29] Thanh Duong, N., Van Hao, D. "Consolidation Characteristics of Artificially Structured Kaolin-Bentonite Mixtures with Different Pore Fluids", Advances in Civil Engineering, 2020, Article ID: $8856404,2020$. https://doi.org/10.1155/2020/8856404

[30] Duong, N. T., Hai, N. V. "Residual Strength of Weakly Cemented Kaolin Clay in Multi-stage Ring Shear Test", Arabian Journal for Science and Engineering, 2021. https://doi.org/10.1007/s13369-021-06132-2
[31] JGS "JGS 0560-2009 Method for consolidated constant-volume direct box shear test on soils", Japanese Geotechnical Society, Tokyo, Japan, 2009.

[32] Duong, N. T., Suzuki, M. "Rate Effect on the Residual Interface Strength Between two Different Soil Layers", In: Long, P. D., Dung, N. T. (eds.) Geotechnics for Sustainable Infrastructure Development, Springer, Singapore, 2020, pp. 985-992. https://doi.org/10.1007/978-981-15-2184-3_129

[33] Suzuki, M., Van Hai, N., Yamamoto, T. "Ring shear characteristics of discontinuous plane", Soils and Foundations, 57(1), pp. 1-22, 2017. https://doi.org/10.1016/j.sandf.2017.01.001

[34] Thanh, D. N., Thi, N. N., Van, H. N., Chau, L. N., Tien, P. V., Suzuki, M. "Characteristics of shear strength at the interface between two soil layers in ring shear apparatus", Journal of Materials and Engineering Structures, 7(4), pp. 575-581, 2020.

[35] Vithana, S. B., Gibo, S., Nakamura, S., Kimura, S. "Influence of Laboratory-Created OCR on Large Deformation Shear Strength: Ring Shear Behaviour of Two Types of Landslide Slip Surface Soil", In: GeoFlorida 2010: Advances in Analysis, Modeling \& Design, West Palm Beach, FL, USA, 2010, pp. 3165-3174. https://doi.org/10.1061/41095(365)323

[36] Suzuki, M., Umezaki, T., Kawakami, H. "Relation between residual strength and shear displacement of clay in ring shear test", Doboku Gakkai Ronbunshu, 575, pp. 141-158, 1997. (in Japanese)

[37] Thermann, K., Gau, C., Tiedemann, J. "Shear strength parameters from direct shear tests-influencing factors and their significance", Proceeding of International Association for Engineering Geology and the Environment 2006, Nottingham, UK, 2006, Article No. 484.

[38] Della, N., Missoum, H., Arab, A., Belkhatir, M. "Experimental study of the overconsolidation and saturation effects on the mechanical characteristics and residual strength of Chlef river sandy soil", Periodica Polytechnica Civil Engineering, 54(2), pp. 107-116, 2010. https://doi.org/10.3311/pp.ci.2010-2.06

[39] Li, Y. R., Aydin, A. "Shear zone structures and stress fluctuations in large ring shear tests", Engineering Geology, 167, pp. 6-13, 2013. https://doi.org/10.1016/j.enggeo.2013.10.001

[40] Ho, D. Y., Fredlund, D. G. "Increase in strength due to suction for two Hong Kong soils", In: Proceedings of the ASCE specialty conference on engineering and construction in tropical and residual soils, Honolulu, HI, USA, 1982, pp. 263-296.

[41] Nishimura, T., Fredlund, D. G. "Relationship between shear strength and matric suction in an unsaturated silty soil", In: Rahardjo, H., Toll, D. G., Leong, E. C. (eds.) Unsaturated Soils for Asia, CRC Press, London, UK, 2020, pp. 563-568.

[42] Peterson, R. W. "The influence of soil suction on the shear strength of unsaturated soil", Department of the Army, Waterways Experiment Station, Corps of Engineers, Vicksburg, MS, USA, Rep. GL-90-17, 1990.

[43] Han, J., Dano, C., Hicher, P.-Y., Yin, Z.-Y. "Strain-rate Dependency of Shear Strength for a Highly Overconsolidated Clay", In: Soil Behavior and Geomechanics, Geo-Shanghai 2014, Shanghai, China, 2014, pp. 343-352. https://doi.org/10.1061/9780784413388.035 